\title{
IGF-I e IgG Séricos e nas Secreções Lácteas em Vacas Tratadas com rbST no Período Pré-Parto ${ }^{1}$
}

\author{
Patricia Pauletti², Adriana Regina Bagaldo ${ }^{3}$, Liris Kindlein ${ }^{4}$, Cláudia Cristina Paro de Paz ${ }^{5}$, \\ Dante Pazzanese Duarte Lanna ${ }^{6}$, Raul Machado Neto ${ }^{7}$
}

\begin{abstract}
RESUMO - Foram utilizadas 42 vacas holandesas gestantes e multíparas, distribuídas ao acaso em dois grupos, com o objetivo de se determinar possíveis alterações na concentração de IGF-I no colostro e nas secreções lácteas em resposta a mudanças na concentração sérica de IGF-I pré-parto, além de se avaliar comparativamente a flutuação sérica pré-parto de IGF-I em relação a IgG. O grupo tratado $(\mathrm{n}=21)$ recebeu $500 \mathrm{mg}$ de somatotropina bovina recombinante (rbST) e o grupo controle $(\mathrm{n}=21)$ injeções de vitamina E. Os tratamentos foram iniciados 35 dias pré-parto e repetidos a cada 14 dias até o parto. Semanalmente, até o parto, avaliou-se o escore corporal (EC) e coletaram-se amostras de sangue da veia mamária. Foram amostrados o colostro e as secreções lácteas diariamente por sete dias pósparto. O EC e a concentração sérica de ácidos graxos não-esterificados não diferiram entre os grupos. O grupo rbST apresentou maiores concentrações séricas de IGF-I na segunda e quarta semanas após o início dos tratamentos, não sendo encontradas diferenças entre os tratamentos ao parto. A concentração de IGF-I foi superior no colostro das vacas tratadas com rbST, não diferindo nas secreções subseqüentes. As concentrações séricas de IgG não diferiram entre tratamentos durante todo o período experimental, assim como as do colostro e demais secreções lácteas. As concentrações séricas de IGF-I e IgG variaram em função do período experimental, diferindo na amplitude e refletindo as grandes mudanças que ocorrem no último mês de gestação.
\end{abstract}

Palavras-chave: colostro, fator de crescimento semelhante à insulina-I, imunoglobulinas, somatotropina

\section{IGF-I and IgG Serum Concentrations and in Mammary Secretions in Cows Treated with rbST Prepartum}

\begin{abstract}
Forty-two Holstein cows, pregnants and multiparous, wereassigned randomly to two groups to determine the possible alterations of IGF-I concentration in colostro and mammary secretions by changes in pre-partum blood serum IGF-I concentration, and also to compare its temporal changes with the serum immunoglobulin $\mathrm{G}(\mathrm{IgG})$ in pre-partum period. The treated group ( $\mathrm{n}=21)$ received $500 \mathrm{mg}$ of recombinant bovine somatotropin ( $\mathrm{rbST}$ ), and the control group $(\mathrm{n}=21)$ vitamin E injections. The treatments had been initiated 35 days prepartum and repeated each 14 days until partum. Weekly it was evaluated body condition scores and was collected blood by mammary venepuncture until partum. Colostrum and mammary secretions were collected daily for seven days pos-partum. Body condition scores and nonesterified fatty acid concentration did not differ between the groups. To the rbST group IGF-I concentration was superior on second and fourth weeks after the treatment had been initiated. However, no treatment differences were found at partum. Concentration of IGF-I was superior in colostrum of cows treated with rbST, but it did not differ in subsequent mammary secretions. IgG serum concentration did not differ between treatments during the experimental period, neither in colostrum and subsequent mammary secretions. IGF-I and IgG serum concentrations showed different responses according to the experimental period, which differed at the range and reflected the main changes that happened at the last month of gestation.
\end{abstract}

Key Words: colostrum, immunoglobulins, insulin like growth factor-I, somatotropin

\footnotetext{
1 Trabalho financiado pela FAPESP.

2 Eng. Agrôn., Ph.D., Depto. de Zootecnia ESALQ-USP, Av. Pádua Dias, 11, Caixa Postal 9, CEP: 13418-900 Piracicaba, SP, Tel (19) 3429 4260 Fax (19) 3429 4338, E-mail: ppaulett@bol.com.br

3 Zootecnista, Ph.D., Depto. de Zootecnia, ESALQ-USP, Av. Pádua Dias, 11, Caixa Postal 9, CEP: 13418-900 Piracicaba, SP, Tel (19) 3429 4260 Fax (19) 3429 4338, E-mail: arbagaldo@bol.com.br

${ }^{4}$ Médica Veterinária, Depto. de Zootecnia, ESALQ-USP, Av. Pádua Dias, 11, Caixa Postal 9, CEP: 13418-900 Piracicaba, SP, Tel (19) 3429 4260 Fax (19) 3429 4338, E-mail: Ikindlei@esalq.usp.br

${ }^{5}$ Zootecnista, Ph.D., Pesquisador Científico - SAA-APTA - Instituto de Zootecnia - Av. Bandeirantes, 2419 Vila Virgínia CEP 14030-670 Ribeirão Preto,SP, Tel (16) 637 1849, E-mail: ccppaz.ddd@apta.sp.gov.br

${ }^{6}$ Eng. Agrôn., Prof. Dr. Associado Depto. de Zootecnia, ESALQ-USP, Av. Pádua Dias, 11, Caixa Postal 9, CEP $13418-900$ Piracicaba, SP, Tel (19) 34294455 Fax (19) 3429 4285, E-mail: dplanna@esalq.usp.br

${ }^{7}$ Eng. Agrôn., Prof. Dr. Titular Depto. de Zootecnia, ESALQ-USP, Av. Pádua Dias, 11, Caixa Postal 9, CEP 13418-900 Piracicaba, SP, Tel (19) 34294260 Fax (19) 3429 4338, E-mail: rmachado@esalq.usp.br
} 


\section{Introdução}

O colostro é a primeira secreção láctea liberada após o parto e, em bovinos, consiste da mistura de secreções da glândula mamária e elementos do soro sangüíneo, principalmente imunoglobulinas, que se acumulam durante o período pré-parto. O colostro é importante para a sobrevivência do recém-nascido, uma vez que as imunoglobulinas maternas presentes nesta secreção garantem níveis iniciais de anticorpos que viabilizam, em grande parte, essa sobrevivência (Husband et al., 1972; Nocek et al., 1984; Machado Neto et al., 1997; Quigley \& Drewry, 1998; Pauletti et al., 2002; Quigley et al., 2002).

Além de anticorpos e nutrientes, o colostro e o leite possuem grande variedade de proteínas, peptídeos e esteróides com atividade biológica, os quais ocorrem em maiores concentrações nas secreções pré-parto e no colostro (Vega et al., 1991; Grosvenor et al., 1993; Odle et al., 1996). Entre os peptídeos bioativos das secreções lácteas, estão os fatores de crescimento semelhantes à insulina I e II (IGFs), que possuem numerosas funções em todos os estádios de desenvolvimento, tanto como mediadores locais do desenvolvimento da glândula mamária como pelo fato de que sua alta concentração no colostro e a presença de receptores específicos para IGF-I no intestino de recémnascidos permitem que estes peptídeos atuem como mediadores maternos de crescimento e desenvolvimento no início da vida (Grosvenor et al., 1993; Hossner et al., 1997; LeRoith, 1999). Tem-se observado semelhança na flutuação sérica de IGF-I e IgG durante o período pré-parto, com maiores concentrações de IGFI nas secreções lácteas coincidindo com o período de máximo transporte das imunoglobulinas para a glândula mamária, sugerindo um mecanismo semelhante de transferência desses elementos da circulação para o tecido mamário (Brandon et al., 1971; Vega et al., 1991; Hadsell et al., 1993).

Aumento nas concentrações de IGF-I sérico e nas secreções lácteas tem sido observado em vacas leiteiras tratadas com somatotropina bovina recombinante (rbST). O tratamento com rbST aumenta o IGF-I intracelular em células epitelias mamárias, sugerindo que o mesmo pode ser transportado para essas células (Glimm et al., 1988). Hadsell et al. (1993) demonstraram que o aumento do IGF-I circulante, após tratamento com rbST no período seco de vacas Holandesas, refletiu também em aumento do IGF-I nas secre- ções lácteas. O total de IGF-I secretado aumentou em três vezes e a sua concentração no colostro em $40 \%$.

O manejo tem sido orientado para o consumo cada vez maior e mais precoce do colostro de alto valor imunológico, assegurando a proteção inicial do recém-nascido, sem avaliar os outros fatores que acompanham essa secreção e que podem influenciar o início do desenvolvimento do animal. O presente trabalho teve como objetivos determinar se as concentrações de IGF-I no colostro e nas secreções lácteas podem ser alteradas em resposta à mudanças na concentração sérica de IGF-I pré-parto, avaliando-se comparativamente a flutuação sérica pré-parto de IGF-I em relação a IgG.

\section{Material e Métodos}

Foram utilizadas 42 vacas da raça Holandesa, gestantes e multíparas, distribuídas ao acaso em dois grupos. O grupo tratado $(\mathrm{n}=21)$ recebeu $500 \mathrm{mg}$ de somatotropina bovina recombinante (rbST - BoostinCoopers) aplicados na fossa ísquio retal a partir de 35 dias pré-parto e a cada 14 dias, enquanto os animais do grupo controle $(n=21)$ receberam injeções $(2 \mathrm{~mL})$ de vitamina $\mathrm{E}$ (Monovin-E acetato de DL-a-tocoferol $2 \mathrm{mg} / 20 \mathrm{~mL}$ ), aplicadas na fossa ísquio retal, nas mesmas datas de aplicação do rbST.

As vacas permaneceram em piquetes de Coastcross e consumiram ração balanceada ad libitum, tendo seu escore corporal (EC) acompanhado semanalmente, de acordo com Smith et al. (1982), classificando-se o EC em uma escala numérica de 1 a 5 , $1=$ muito magro e $5=$ muito obeso, respectivamente. A unidade de EC utilizada nesta avaliação foi 0,5 . Foram coletadas, semanalmente, amostras de sangue da veia mamária, com início 35 dias pré-parto até o parto, que foram centrifugadas. O soro resultante foi transferido para três frascos devidamente identificados e mantidos a uma temperatura de $-20^{\circ} \mathrm{C}$. Foram coletadas amostras do colostro e das secreções lácteas até sete dias pós-parto, sendo cada uma transferida para três frascos devidamente identificados e mantidos a uma temperatura de $-20^{\circ} \mathrm{C}$.

A fração IgG sérica foi quantificada pelo método de imunodifusão radial descrita por Mancini et al. (1965). A fração IgG do colostro e das secreções lácteas foi quantificada pelo método de imunodifusão radial descrita por Mancini et al. (1965), modificado por Besser et al. (1985). A técnica consiste na leitura 
do diâmetro formado pela reação do anticorpo da amostra com o anti-IgG (anti-bovine IgG Sigma Chemical Company) em meio de ágar, comparandose com diâmetros padrões pré-estabelecidos (bovine IgG Sigma Chemical Company). As amostras foram analisadas em duplicata, os diâmetros de precipitação foram medidos e registrados em milímetros e o valor médio foi utilizado para se obter as concentrações de $\mathrm{IgG}$ em $\mathrm{mg} / \mathrm{mL}$.

A quantificação da proteína total sérica foi determinada pelo método de biureto, segundo Reinhold (1953). As leituras foram realizadas em espectrofotômetro, com o comprimento de onda ajustado para $545 \mathrm{~nm}$ para cada bateria de amostras, estabelecendo-se uma curva padrão relacionando concentrações conhecidas de proteína (albumina bovina - Sigma Chemical Company) a valores de absorbância obtidos das amostras. As amostras foram analisadas em duplicata, sendo o valor médio utilizado para se obter as concentrações de proteína total em $\mathrm{g} / 100 \mathrm{~mL}$ de soro.

As concentrações de IGF-I no soro, no colostro e nas secreções lácteas foram quantificadas por ensaio imunoradiométrico pós-extração, empregando-se utilizando-se o kit DSL-5600 (Diagnostic Systems Laboratories, Inc.). O colostro e as secreções lácteas foram centrifugados previamente por 30 minutos a 13.000 g. Para cada bateria de amostras estabeleceuse uma curva padrão, relacionando concentrações conhecidas de IGF-I às concentrações das amostras, adicionando-se também dois controles que continham alta e baixa concentrações de IGF-I e que serviram para a validação do ensaio. As amostras foram analisadas em duplicata e a contagem foi realizada em um contador gama (Automatic Gamma Counter 1470, Wizard TM Wallac), sendo o valor médio utilizado para se obter as concentrações de IGF-I em ng/mL.

As concentrações séricas de ácidos graxos nãoesterificados (AGNE) foram determinadas pelo do método enzimático colorimétrico, utilizando-se o kit NEFAc (Wako 994-75409E). A leitura da absorbância foi realizada em espectrofotômetro UV-1601 PC SHIMADZU com comprimento de onda ajustado em $545 \mathrm{~nm}$. As amostras foram analisadas em duplicata, sendo o valor médio utilizado para se obter as concentrações de AGNE mmol/L.

Adotou-se o delineamento experimental inteiramente casualizado em parcelas subdivididas no tempo, sendo o efeito do tratamento hormonal com somatotropina ou do tratamento controle com vitamina $\mathrm{E}$ aplicado às parcelas $\mathrm{e}$ as medidas repetidas no tempo consideradas como subparcelas. Os dados foram analisados pelo procedimento PROC MIXED do programa SAS (1991), em que a condição corporal das vacas, as variáveis séricas e as secreções lácteas foram submetidas à análise de variância para este delineamento. Para a avaliação de diferenças entre médias, foram efetuados contrastes entre pares de médias, utilizando-se o método Tukey. Para todas as análises, adotou-se o nível de significância de 5\% $(\mathrm{P}<0,05)$. Foi utilizada a transformação das variáveis séricas IgG (raiz quadrada) e IGF-I (log na base 10), pois não foi atendida a suposição de linearidade feita em análises empregando-se os modelos lineares. Análises de correlação, Pearson e Spearman, foram realizadas para se verificar associações de interesse entre as variáveis séricas.

\section{Resultados e Discussão}

O escore corporal (EC) médio semanal dos animais distribuídos nos dois grupos é apresentado na Tabela 1.

O EC dos animais do início do tratamento até o parto não diferiu entre os grupos $(\mathrm{P}>0,05)$, não sendo observadas mudanças do EC ao longo do período experimental ( $\mathrm{P}>0,05)$, com valor médio de 3,45 , o que está de acordo com o proposto por Quigley \& Drewry (1998) para vacas durante seu período seco, os quais propõem um manejo nutricional durante os dois últimos meses de gestação capaz de proporcionar às vacas EC 3,5. Putnam et al. (1999) avaliaram o efeito da suplementação com 13 e 17\% de proteína bruta na matéria seca, aliada ao uso de rbST, sobre o EC de vacas leiteiras no período final de gestação e observaram resultados semelhantes ao deste trabalho, em que o nível médio de proteína bruta utilizado foi de $15 \%$. Os autores não encontraram diferenças quanto ao EC entre os animais tratados e os animais controle, observando-se valor médio de 3,5. Vallimont et al. (2001) observaram resultados semelhantes com suplementação de rbST a partir de 28 dias pré-parto.

Hadsell et al. (1993) trabalharam com vacas secas tratadas com hormônio de crescimento a partir de oito semanas pré-parto e não observaram diferenças no peso dos animais tratados em relação aos animais controle, registrando-se variações apenas quanto à perda de peso nos animais submetidos à restrição 
Tabela 1 - Escore corporal durante o período de tratamento e na data de parição Table 1 - Body condition score during the treatment period and at partum

\begin{tabular}{|c|c|c|c|c|c|c|c|c|c|}
\hline \multirow[b]{2}{*}{ Trat $^{1}$} & \multicolumn{5}{|c|}{$\begin{array}{l}\text { Período de tratamento (semanas) } \\
\text { Treatment period (weeks) }\end{array}$} & \multirow[b]{2}{*}{$\begin{array}{l}\text { Parto } \\
\text { Partum }\end{array}$} & \multirow[b]{2}{*}{$\begin{array}{l}\text { Média geral } \\
\text { Overall mean }\end{array}$} & \multicolumn{2}{|c|}{$\mathrm{P}^{2}$} \\
\hline & $1^{\mathrm{a}}$ & $2^{\mathrm{a}}$ & $3^{\mathrm{a}}$ & $4^{\mathrm{a}}$ & $5^{\mathrm{a}}$ & & & Trat & $\begin{array}{c}\text { Período } \\
\text { Period }\end{array}$ \\
\hline Controle & 3,56 & 3,48 & 3,46 & 3,40 & 3,31 & 3,30 & 3,42 & 0,67 & 0,62 \\
\hline $\begin{array}{l}\text { Control } \\
\text { ST } \\
\text { ST }\end{array}$ & 3,35 & 3,46 & 3,61 & 3,52 & 3,50 & 3,40 & 3,47 & & \\
\hline $\begin{array}{l}\text { Média período } \\
\text { Period means }\end{array}$ & 3,45 & 3,47 & 3,53 & 3,46 & 3,40 & 3,36 & & & \\
\hline $\mathrm{DP}^{3}$ & 0,37 & 0,37 & 0,33 & 0,38 & 0,44 & 0,33 & & & \\
\hline
\end{tabular}

${ }^{1}$ Trat: Controle - tratamento com vitamina E, ST - tratamento com rbST (somatotropina bovina recombinante); ${ }^{2} \mathrm{P}=$ probabilidade; ${ }^{3} \mathrm{DP}=$ desvio-padrão.

${ }^{1}$ Trat: Control - vitamin E treatment, ST - rbST treatment (recombinant bovine somatotropin); ${ }^{2} P=$ probability; ${ }^{3} D P=$ standard deviation.

alimentar no mesmo período. Gulay et al. (2003), trabalhando com vacas leiteiras recebendo baixa dosagem de rbST durante o período pré-parto $(10,2 \mathrm{mg}$ rbST/dia; $28 \pm 3$ dias antes da data prevista de parição), também não observaram efeito do tratamento no ganho de peso dos animais ou EC.

As concentrações médias de ácidos graxos nãoesterificados (AGNE) dos animais distribuídos nos dois grupos, em função do tratamento hormonal, são apresentadas na Figura 1.

As concentrações séricas de AGNE ao longo do período experimental não diferiram entre os tratamentos $(\mathrm{P}>0,05)$, com efeito significativo somente de período $(\mathrm{P}<0,05)$. As concentrações médias de AGNE em todos os períodos e no parto, independentemente do tratamento, foram superiores à encontrada por Ronge \& Blum (1988), que observaram concentração média de $331 \mathrm{mmol} / \mathrm{L}$ de AGNE em vacas durante o período pré-parto.

Putnam et al. (1999), suplementando vacas com rbST durante seu período seco a partir de 28 dias préparto, encontraram valores de AGNE semelhantes aos obtidos neste estudo, com níveis médios de 600 $\mathrm{mmol} / \mathrm{L}$ na semana que antecedeu o parto. Como no presente estudo, apesar das altas concentrações de AGNE, os autores também não observaram diferenças em função do tratamento no EC dos animais. Vallimont et al. (2001), por sua vez, em ensaio com vacas recebendo somatotropina com início 28 dias pré-parto, observaram valores muito inferiores de AGNE aos supracitados, com média de 134,3 mmol/L. Essas diferenças nos níveis séricos de AGNE podem estar relacionadas a dose aplicada do hormônio e ao

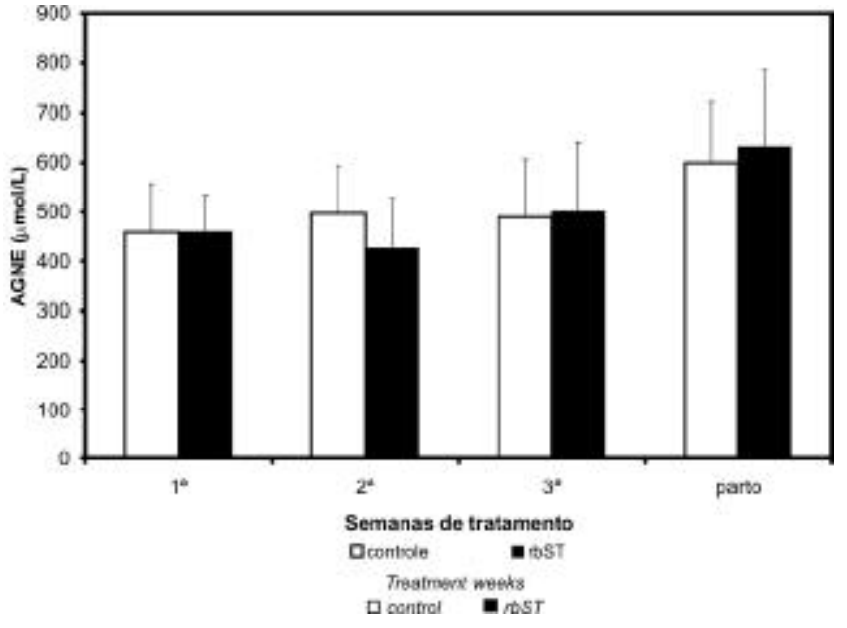

Figura 1 - Concentrações séricas de ácidos graxos nãoesterificados (média \pm desvio-padrão) durante o período de tratamento e na data do parto.

Figure 1 - Nonesterified free fatty acids serum concentrations (mean \pm standard deviation) during the treatment period and at partum.

intervalo de aplicação adotados, assim como ao balanço energético do animal.

O tratamento com rbST pode ocasionar mobilização de AGNE, embora diferentes respostas em relação à administração do hormônio durante o período pré-parto possam estar diretamente relacionadas ao estado nutricional dos animais. Vacas com balanço energético negativo apresentam aumento na perda de AGNE, indicando maior mobilização de reservas corporais, sem alteração na lipogênese, enquanto vacas em balanço energético positivo, têm a maior parte dos efeitos da somatotropina relacionados à redução na síntese de gorduras (Bauman et al., 
1988; Lanna et al., 1995). Entretanto, Gallo \& Block (1990) constataram que a administração de rbST resultou em persistente aumento na concentração sérica de AGNE, independentemente do balanço energético do animal antes do início do tratamento.

As médias das concentrações séricas de IGF-I e IgG encontram-se na Tabela 2.

As concentrações séricas de IGF-I diferiram entre os tratamentos, entre os períodos, com interação significativa também entre tratamento e período $(\mathrm{P}<0,05)$. Neste trabalho, os níveis séricos de IGF-I na primeira semana foram semelhantes para os grupos controle e tratado (rbST), ou seja, 82,75 e 71,66 $\mathrm{ng} / \mathrm{mL}$, respectivamente, indicando homogeneidade entre os grupos na concentração sérica dessa variável no início do tratamento. No entanto, a média observada para o período $(77,02 \mathrm{ng} / \mathrm{mL})$ foi inferior à encontrada por Vega et al. (1991), que, avaliando vacas com período seco de aproximadamente $60 \pm 5$ dias, encontraram o pico de concentração de IGF-I sérico de $163 \mathrm{ng} / \mathrm{mL}$ aos 34 dias pré-parto.

Os níveis circulantes de IGF-I variaram consideravelmente nos dois grupos entre o início do período experimental e o parto. No grupo controle, observou- se uma amplitude de variação de $84 \%$ entre os valores máximo e mínimo, com concentrações médias de $82,75 \mathrm{ng} / \mathrm{mL}$ para a primeira semana e $13,19 \mathrm{ng} / \mathrm{mL}$ ao parto. Até a terceira semana, os animais desse grupo não apresentaram diferenças nas concentrações séricas de IGF-I, observando-se queda a partir da quarta semana. Ronge \& Blum (1988) avaliaram vacas leiteiras durante o período pré-parto e encontraram concentração sérica de $40 \mathrm{ng} / \mathrm{mL}$ de IGF-I duas semanas pré-parto. Valores próximos foram encontrados neste trabalho para o grupo controle, uma vez que as concentrações nas duas últimas semanas que antecederam o parto foram de 32,91 e $36,14 \mathrm{ng} / \mathrm{mL}$, respectivamente.

A amplitude de variação encontrada para o grupo tratado com rbST foi de 92\%, superior à encontrada para os animais do grupo controle, com valores máximo e mínimo variando entre $203,89 \mathrm{ng} / \mathrm{mL}$, para a segunda semana, e 16,95 ng/mL, no parto. Esse grupo apresentou níveis de IGF-I superiores $(\mathrm{P}<0,05) \mathrm{em}$ relação ao grupo controle na segunda e na quarta semanas após o início do tratamento, em resposta às aplicações do rbST (203,89 vs. 80,00 ng/mL e 121,28 vs. $32,91 \mathrm{ng} / \mathrm{mL}$, respectivamente).

Tabela 2 - Concentrações séricas de IGF-I (ng/mL) e IgG $(\mathrm{mg} / \mathrm{mL})$ durante o período de tratamento e na data do parto Table 2 - Serum IGF-I $(\mathrm{ng} / \mathrm{mL})$ and $\lg G(\mathrm{mg} / \mathrm{mL})$ concentrations during the treatment period and at partum

\begin{tabular}{|c|c|c|c|c|c|c|c|c|c|c|}
\hline \multirow[b]{2}{*}{ Trat $^{1}$} & \multicolumn{5}{|c|}{$\begin{array}{l}\text { Período de tratamento (semanas) } \\
\text { Treatment period (weeks) }\end{array}$} & \multirow[b]{2}{*}{$\begin{array}{c}\text { Parto } \\
\text { Partum }\end{array}$} & \multirow[b]{2}{*}{$\begin{array}{l}\text { Média geral } \\
\text { Overall mean }\end{array}$} & \multicolumn{2}{|r|}{$\mathrm{P}^{2}$} & \multirow[b]{2}{*}{$\begin{array}{l}\text { Trat x Período } \\
\text { Trat } x \text { Period }\end{array}$} \\
\hline & $1^{\mathrm{a}}$ & $2^{\mathrm{a}}$ & $3^{\mathrm{a}}$ & $4^{\mathrm{a}}$ & $5^{\mathrm{a}}$ & & & Trat & $\begin{array}{l}\text { Período } \\
\text { Period }\end{array}$ & \\
\hline \multicolumn{11}{|c|}{ IGF-I(ng/mL) } \\
\hline Controle & $82,75^{\mathrm{A}}$ & $80,00^{\mathrm{aA}}$ & $63,67^{\mathrm{A}}$ & $32,91^{\mathrm{aB}}$ & $36,14^{\mathrm{B}}$ & $13,19^{\mathrm{C}}$ & 43,33 & 0,02 & 0,01 & 0,01 \\
\hline $\begin{array}{l}\text { Control } \\
\text { ST }\end{array}$ & $71,66^{\mathrm{A}}$ & $203,89^{b B}$ & $80,42^{\mathrm{A}}$ & $121,28^{b C}$ & $35,97^{\mathrm{D}}$ & $16,95^{\mathrm{D}}$ & 66,56 & & & \\
\hline $\begin{array}{l}S T \\
\text { Média período } \\
\text { Period mean }\end{array}$ & 77,02 & 127,70 & 71,56 & 63,18 & 36,05 & 14,95 & & & & \\
\hline \multicolumn{11}{|c|}{$\operatorname{IgG}(\mathrm{mg} / \mathrm{mL})$} \\
\hline Controle & 35,13 & 35,40 & 34,76 & 31,40 & 32,98 & 27,74 & 32,84 & 0,25 & 0,01 & 0,96 \\
\hline
\end{tabular}

abMédias seguidas de letras distintas na mesma coluna diferem $(P<0,05)$ entre si pelo teste $F$.

ab Means within a column with different $(P<.05)$ small letters are different by $F$ test.

$A B C D$ Médias seguidas de letras distintas na mesma linha diferem $(P<0,05)$ entre si pelo teste Tukey.

$A B C D$ Means within a row with different $(P<.05)$ capital letters are different $(P<.05)$ by Tukey test.

${ }^{1}$ Trat: - tratamento controle com vitamina E, ST - tratamento com rbST (somatotropina bovina recombinante); ${ }^{2} \mathrm{P}=$ probabilidade.

${ }^{1}$ Trat: Control - vitamin E treatment, ST - rbST treatment (recombinant bovine somatotropin); ${ }^{2} P=$ probability. 
Hadsell et al. (1993) aplicaram rbST durante o período pré-parto e encontraram diferenças na concentração de IGF-I em relação aos animais controle na segunda e quarta semanas após o início do tratamento (279,53 vs. $121,15 \mathrm{ng} / \mathrm{mL}$ e 191,53 vs. 103,07 $\mathrm{ng} / \mathrm{mL}$, respectivamente). Os valores encontrados por foram superiores aos deste estudo, mas aqueles autores iniciaram o experimento sete semanas préparto, quando os animais ainda podem apresentar elevação dos níveis circulantes de IGF-I, enquanto, neste experimento, o tratamento teve início cinco semanas pré-parto, quando as concentrações séricas de IGF-I tendem a se reduzir até a parição. Hadsell et al. (1993) também observaram valores mais altos de IGF-I na data do parto em relação aos deste trabalho $(67,77$ e $25,77 \mathrm{ng} / \mathrm{mL}$ para animais tratados com rbST e controles, respectivamente).

Vega et al. (1991) acompanharam a flutuação sérica de IGF-I em vacas leiteiras que não receberam qualquer tratamento hormonal ou tiveram restrição alimentar durante o seu período seco e relataram que as maiores mudanças no IGF-I sérico ocorreram quatro dias antes e três dias após o parto, com redução de $70 \%$ nos níveis circulantes e concentrações séricas de IGF-I cinco dias pré-parto variando de 24 a $81 \mathrm{ng} / \mathrm{mL}$.

Nos animais do grupo controle, os níveis de IGF-I sérico das duas últimas semanas em relação à data do parto apresentaram redução $(\mathrm{P}<0,05)$ de aproximadamente, $60 \%$. Os animais do grupo tratado com somatotropina, por sua vez, não apresentaram diferenças entre a última semana de tratamento e a data do parto, o que pode estar relacionado à proximidade entre a última aplicação do hormônio e o parto. As médias observadas ao parto, 16,95 e 13,19 ng/mL para animais tratados com rbST e para o grupo controle, respectivamente, não diferiram entre si $(\mathrm{P}<0,05)$.

Os resultados deste experimento refletem aumento da concentração de IGF-I em resposta às aplicações do rbST, uma vez que a supremacia dos efeitos relacionados à hipertrofia e à proliferação celular, em resposta à administração de rbST, é primariamente mediada pelo IGF-I. (Glimm et al., 1988; Prosser et al., 1989; Burton et al., 1994). No entanto, esse aumento é dependente, também, do plano de nutrição, incluindo porcentagem de energia e proteína na dieta. Animais bem nutridos respondem ao tratamento com rbST, elevando os níveis séricos de IGF-I, enquanto animais com alguma restrição nutricional exibem pou- co ou nenhum aumento nas concentrações de IGF-I (Breier et al., 1988).

As concentrações séricas de IgG não diferiram entre os grupos $(\mathrm{P}>0,05)$. Verificou-se efeito somente de período $(\mathrm{P}<0,05)$, com redução significativa de $20 \%$ nos níveis séricos circulantes entre a primeira semana do período experimental e o parto, (36,90 vs. $29,11 \mathrm{mg} / \mathrm{mL}$, respectivamente).

Os resultados deste estudo confirmam relatos de queda de 10 a $30 \%$ nos níveis de imunoglobulinas totais séricas em várias espécies associadas ao parto (Larson \& Kendal, 1957; Dixon et al., 1961; Jeffcott, 1972; Sasaki et al., 1976). Entretanto, Brandon et al. (1971), analisando as subclasses de IgG, observaram redução em torno de $50 \%$ na concentração sérica de $\mathrm{IgG}_{1}$ entre a terceira semana pré-parto e o parto, ao passo que os níveis de $\mathrm{IgG}_{2}$ mantiveram-se inalterados.

Considerando-se as altas concentrações da variável IgG na primeira semana do período experimental (35,13 e $38,71 \mathrm{mg} / \mathrm{mL}$, grupo controle e rbST, respectivamente), constata-se que os animais apresentavam boa condição imunológica no início do experimento, refletindo manejo adequado no período préparto. Apesar da elevada concentração inicial, a redução na concentração sérica de $\mathrm{IgG}$ entre o início do período experimental e o parto foi de $8 \mathrm{mg} / \mathrm{mL}$, semelhante à verificada em outros estudos, nos quais o nível médio de anticorpos séricos variou de 20 a 25 $\mathrm{mg} / \mathrm{mL}$ no último mês antes do parto (Brandon et al., 1971; Sasaki et al., 1976; Hadsell et al., 1993).

A redução na concentração sérica de IgG durante o período pré-parto está associada à remoção ativa desses anticorpos pela glândula mamária (Sasaki et al., 1976). Dixon et al. (1961), Brandon et al. (1971) e Foley \& Otterby (1978) afirmaram que, durante as três últimas semanas pré-parto, 500 a 700 gramas de imunoglobulinas são transferidos do sangue para as secreções lácteas.

Assim como para IgG, a remoção ativa de IGF-I da corrente sangüínea pela glândula mamária no período pré-parto é sugerida como um dos mecanismos envolvidos no declínio do IGF-I circulante (Prosser et al. 1989; Vega et al., 1991). Entretanto, a concentração sérica de IGF-I após o parto permanece baixa por algumas semanas, fato relacionado ao decréscimo no balanço energético que altera os níveis circulantes de IGF-I (Vega et al., 1991). A hipogamaglobulinemia pré-parto não é influenciada pelo balanço energético do animal, sendo prontamente corrigida com a con- 
centração de anticorpos materna, retornando a níveis normais nas primeiras semanas após o parto, entre 20 e $30 \mathrm{mg} / \mathrm{mL}$ (Schmidt, 1971; Sasaki et al., 1976).

Além do efeito direto da administração de rbST nos níveis circulantes de IGF-I, alguns trabalhos têm comprovado efeitos indiretos, como alterações no sistema imune do animal. Burton et al. (1991a) aplicaram rbST na quarta e quinta semanas de lactação, enquanto Hadsell et al. (1993) forneceram durante o período pré-parto e, nos dois experimentos, verificouse um aumento na concentração sérica de $\operatorname{IgG}$, fato não observado neste trabalho, em que o IgG sérico no período pré-parto não diferiu entre os tratamentos ( $\mathrm{P}>0,05)$. Burton et al. (1991b), avaliando a resposta de vacas lactantes tratadas com rbST na proliferação de linfócitos sangüíneos como um parâmetro imunológico para avaliação do efeito do hormônio no sistema imune, concluíram que a maior proliferação das células linfocitárias exige tratamento a longo prazo e que as maiores concentrações de IGF-I sérico não estariam relacionadas à resposta proliferativa dos linfócitos. Por outro lado, Burton et al. (1992), trabalhando nas mesmas condições experimentais, não observaram efeito do rbST na resposta humoral do sistema imune. Portanto, ainda não está definido o efeito do rbST sobre a concentração de IgG, assim como o possível mecanismo envolvido.

As médias da concentração de proteína total (PT) (g/100 mL) são apresentadas na Figura 2. As concentrações séricas de PT não diferiram entre os tratamentos $(\mathrm{P}>0,05)$ durante o período pré-parto, havendo efeito de período $(\mathrm{P}<0,05)$ e interação entre tratamento e período $(\mathrm{P}<0,05)$.

Nos grupos controle e rbST, foram observadas altas concentrações de PT sérica na primeira semana do período experimental $(9,40 \pm 0,79$ e $9,05 \pm 1,06 \mathrm{~g} /$ $100 \mathrm{~mL}$, respectivamente), o que ocorreu, em parte, como reflexo dos elevados níveis de IgG sérica observados nos animais no mesmo período.

Os animais do grupo controle apresentaram redução $(\mathrm{P}<0,05)$ de $18 \%$ na concentração sérica de PT do início do tratamento até o parto $(9,40$ e 7,74 g/100 mL, respectivamente). Os animais que receberam $\mathrm{rbST}$ apresentaram menor redução $(9 \%, \mathrm{P}<0,05)$ na concentração de PT sérica no mesmo período $(9,05$ e 8,21 $\mathrm{g} / 100 \mathrm{~mL}$, respectivamente). Essa menor amplitude de variação encontrada nos animais do grupo rbST está relacionada ao fato de não se ter observado diferenças entre os níveis de PT a partir da quarta

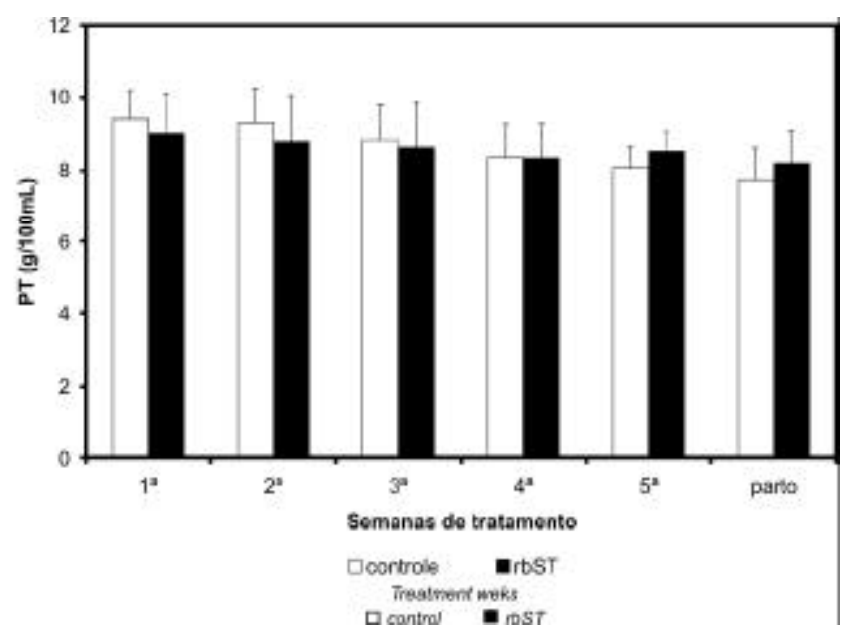

Figura 2 - Concentrações séricas de proteína total (média \pm desvio-padrão) durante o período de tratamento e no parto.

Figure 2 - Total protein serum concentration (mean \pm standard deviation) during the treatment period and at partum.

semana de tratamento até o parto, enquanto os animais do grupo controle apresentaram diferenças significativas no mesmo período. Ronge \& Blum (1988) também verificaram redução da concentração da variável próximo à data de parição, embora com média inferior à encontrada neste estudo, que foi de $6,67 \mathrm{~g} / 100 \mathrm{~mL}$.

Contrariando este estudo, em que os níveis de PT séricos não foram influenciados pelo tratamento hormonal, Rosi \& Pinotti (2002) trabalharam com vacas da raça Holandesa tratadas com rbST durante a lactação e verificaram aumento $(\mathrm{P}<0,05)$ na concentração sérica de proteína total entre a segunda e quinta semanas após o início do tratamento, de 7,89 para $8,14 \mathrm{mg} / 100 \mathrm{~mL}$. Apesar de os autores não terem avaliado a concentração sérica de $\mathrm{IgG}$, o aumento da concentração de proteína total pode estar correlacionado ao aumento da concentração da fração IgG sérica, como em outros estudos (Burton et al., 1991a; Hadsell et al., 1993), o que não observado neste estudo, em que as concentrações séricas de IgG não diferiram entre os tratamentos.

As variáveis PT e imunoglobulinas séricas foram correlacionadas $(\mathrm{P}<0,05)$, considerando-se o período experimental total, com valor de $r=0,27$, independentemente do tratamento, e valores de $r=0,42$ e $r=0,21$, para os grupos controle e rbST, respectivamente, não sendo significativa $(\mathrm{P}>0,05)$ entre as variáveis séricas ao parto. A variável IGF-I não apresentou correlação com PT $(\mathrm{P}>0,05)$ ou com os tratamenos, consideran- 
do-se o período experimental total e o parto, independentemente dos tratamentos.

A concentração de todas as variáveis séricas variou em função do período experimental $(\mathrm{P}<0,05)$, diferindo na amplitude e refletindo as mudanças que ocorrem no último mês de gestação.

Tem-se verificado altas concentrações de IGF-I no colostro de bovinos, com níveis médios de 100 a $500 \mathrm{ng} / \mathrm{mL}$, enquanto, no leite, são inferiores a $40 \mathrm{ng} / \mathrm{mL}$ no leite (Zhao et al., 1991; Vacher \& Blum, 1993; Donovan et al., 1994; Hardon et al., 1997; Blum \& Hammon, 2000). Nesta pesquisa, o objetivo da administração de rbST aos animais durante seu período seco foi de aumentar a concentração sérica de IGFI e, conseqüentemente, as concentrações no colostro e subseqüientes secreções lácteas (Figura 3). O tratamento com rbST elevou $(\mathrm{P}<0,05)$ a concentração de IGF-I no colostro em $30 \%$, quando comparado aos animais controle $(874,53 \pm 335,02$ e $674,15 \pm 269,53$ $\mathrm{ng} / \mathrm{mL}$, respectivamente). As concentrações de IGFI no colostro das vacas tratadas com rbST foram 1,5 a 2 vezes maiores que aquelas observadas em outros experimentos (Malven et al., 1987; Vega et al., 1991).

Hadsell et al. (1993) utilizaram somatotropina em vacas leiteiras a partir de oito semanas antes da data prevista de parição e obtiveram concentração média de IGF-I no colostro de 1116,15 ng/mL. Apesar de essa concentração média ser superior à encontrada neste estudo $(874,53 \mathrm{ng} / \mathrm{mL})$, é importante ressaltar que foi verificado grau de variação entre animais, com valor máximo observado de $1.413,07 \mathrm{ng} / \mathrm{mL}$.

O IGF-I sérico acompanha de forma estreita a oscilação de $\operatorname{IgG}$ no período pré-parto, apresentando redução entre o início do período experimental e o parto, sugerindo a remoção ativa das mesmas da corrente sangüínea para a glândula mamária. No entanto, Hadsell et al. (1993) utilizaram um índice idealizado por Brandon et al. (1971) para calcular a taxa de secreção de IgG:IGF-I sérica em relação à IGF-I:IgG nas secreções lácteas pré-parto e no colostro, com o objetivo de determinar mudanças temporais comparativas entre as duas variáveis e observaram que a diminuição na concentração sérica de $\mathrm{IgG}$ corresponde ao acúmulo dessa proteína nas secreções lácteas, o que pode não ser totalmente verdadeiro para IGF-I. Esta observação e o fato de as secreções lácteas pré-parto apresentarem concentração 20 vezes maior de IGF-I em relação à concentração sérica, sugerem que a difusão de IGF-I do sangue

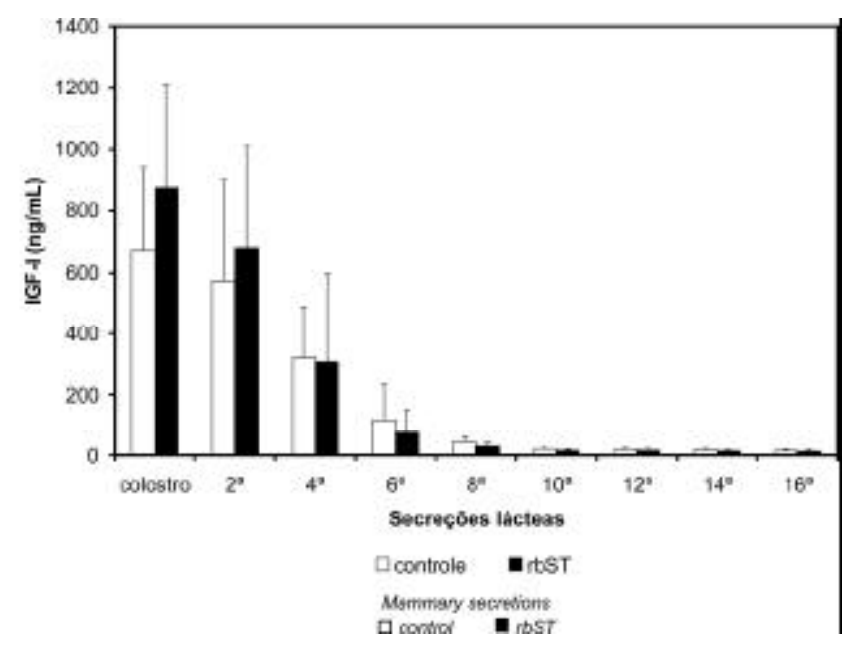

Figura 3 - Concentrações de IGF-I (média \pm desvio-padrão) no colostro e secreções lácteas.

Figure 3 - IGF-I concentration (mean \pm standard deviation) in colostrum and mammary secretions.

para as secreções lácteas pode não explicar totalmente a variação nas mesmas (Malven et al., 1987; Vega et al., 1991; Hadsell et al., 1993).

Além do mecanismo de transferência da corrente sangüínea materna para a glândula mamária, única possibilidade para o acúmulo de $\mathrm{IgG}$, têm-se sugerido que os IGFs presentes nas secreções lácteas podem também se originar da síntese local da glândula e de um mecanismo de difusão acoplado às proteínas de ligação dos IGFs que prolongariam a meia-vida dos IGFs nas secreções lácteas. Além do acúmulo nas secreções lácteas, a alta concentração de IGF-I na glândula mamária durante o final do período seco da vaca sugere a participação do IGF-I como mediador local do crescimento e desenvolvimento das células epiteliais mamárias (Glimm et al., 1988; Simmen et al., 1988; Hadsell et al., 1990; Weber et al., 2000). Campbell et al. (1991) e Weber et al. (2000) demonstraram que explantes de tecido mamário sintetizam e secretam IGF-I e IGFBPs, exclusivamente na porção do estroma, desempenhando um papel parácrino de IGF-I no desenvolvimento do epitélio. Porém, o nível de síntese parece ser muito baixo para explicar a concentração do IGF na secreção láctea (Baumrucker \& Blum, 1993).

As demais secreções lácteas não foram influenciadas pelo tratamento das vacas, verificando-se efeito somente de período $(\mathrm{P}<0,05)$, com redução pronunciada das concentrações nas secreções lácteas a partir do colostro. Até o sétimo dia de coleta, houve queda de $98 \%(\mathrm{P}<0,05)$ em relação à concentração inicial, 
com concentração média de 12,86 ng/mL de IGF-I no leite. Flutuação semelhante de IGF-I nas secreções lácteas foi encontrada por Blum \& Hammon (2000), Hammon et al. (2000) e Sejrsen et al. (2001).

A partir dos dados obtidos, pode-se sugerir que aumentos nos níveis de IGF-I na circulação materna préparto podem não refletir diretamente na condição de mobilização dessa proteína para a glândula mamária, pois o aumento de IGF-I nas secreções lácteas depende de um conjunto de fatores, sobretudo os níveis de hormônio de crescimento, a duração do período seco, a síntese local na glândula mamária, as características de produção e o balanço energético do animal.

As concentrações médias de $\operatorname{IgG}$ referentes ao colostro e às demais secreções lácteas dos animais distribuídos nos dois grupos encontram-se na Figura 4. A concentração de IgG no colostro e subseqüentes secreções não foram influenciadas pelo tratamento nas vacas. Verificou-se somente efeito de período $(\mathrm{P}<0,05)$, com redução progressiva das concentrações de IgG nas secreções lácteas na primeira semana de lactação.

Os resultados confirmam aqueles obtidos por Hadsell et al. (1993), que, apesar de encontrarem efeito do tratamento com rbST sobre os níveis séricos de $\mathrm{IgG}_{1}$ no período pré-parto, não observaram mudanças quanto às concentrações de $\mathrm{IgG}$ no colostro e nas demais secreções. Macewko et al. (2002) trabalharam com animais de corte recebendo somatotropina no período pré-parto e não verificaram diferenças na concentração de $\operatorname{IgG}_{1}$ e IgM no colostro, embora o tratamento tenha apresentado efeito linear $(\mathrm{P}<0,05)$ na concentração de $\mathrm{IgG}_{2}$ nas secreções lácteas, com aumento de $35 \%$. Entretanto, como $\operatorname{IgG}_{2}$ representa apenas uma pequena fração das imunoglobulinas totais presentes no colostro, a elevação de seus níveis nas secreções lácteas pode não ter significado para o animal recém-nascido.

As concentrações médias de IgG observadas no colostro neste trabalho foram de 119,60 $\pm 26,14$ e $115,27 \pm 26,38 \mathrm{mg} / \mathrm{mL}$ para os grupos controle e rbST, respectivamente. Fleenor \& Stott (1980) classificam colostros com teores abaixo de $21,8 \mathrm{mg}$ de imunoglobulinas $/ \mathrm{mL}$ como de baixo valor imunológico e, acima de 49,82 $\mathrm{mg} / \mathrm{mL}$, como de alto valor imunológico. Os valores observados neste estudo encontram-se entre os mais elevados para vacas da raça Holandesa, que variam entre 50 e $90 \mathrm{mg} / \mathrm{mL}$ (Burton et al., 1989; Tyler et al., 1999; Blum \& Hammon, 2000; Morin et al., 2001).

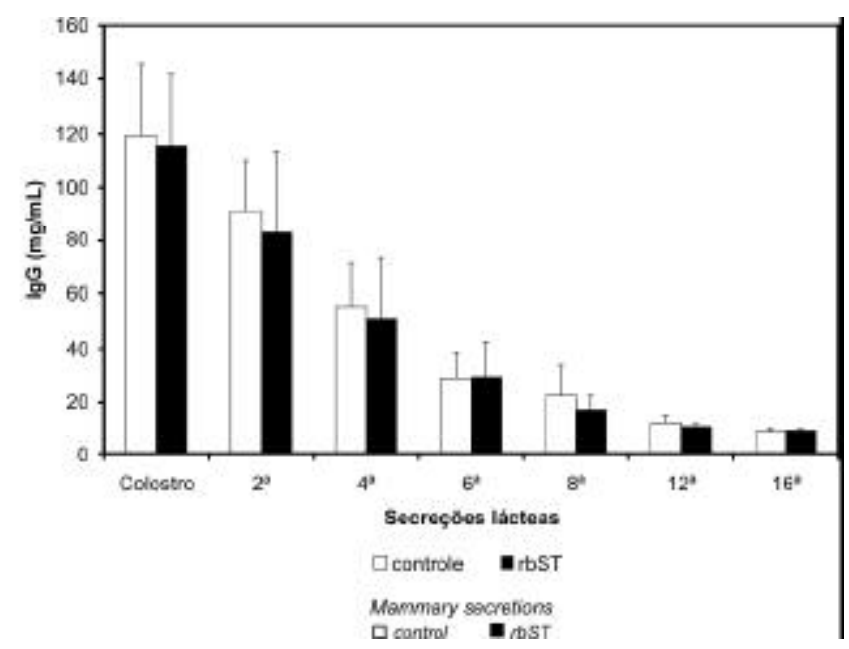

Figura 4 - Concentrações de IgG (média \pm desvio-padrão) no colostro e nassecreções lácteas.

Figure 4 - IgG concentration (mean \pm standard deviation) in colostrum and mammary secretions.

A concentração de imunoglobulinas no colostro é máxima no momento do parto e decresce a cada ordenha no período pós-parto. A concentração média de imunoglobulinas em vacas da raça Holandesa começa a diminuir entre o colostro e 12 a 24 horas após o parto, mas, apesar dessa diminuição, a IgG continua sendo a principal imunoglobulina durante a lactação. $O$ conteúdo de IgG no colostro declina rapidamente, de modo que, 16 horas após o parto, a redução chega a $40 \%$ (Kruse, 1970). Neste trabalho, houve redução de 25 e $55 \% 12$ e 24 horas após o parto, respectivamente, com médias de concentração elevadas $(87,03$ e $52,71 \mathrm{mg} / \mathrm{mL})$. Até o sétimo dia de coleta, observou-se redução de $90 \%$ da concentração inicial, registrando-se, no leite, concentração média de $9,00 \mathrm{mg} / \mathrm{mL}$ de $\mathrm{IgG}$.

\section{Conclusões}

O rbST influenciou somente as concentrações séricas de IGF-I no período pré-parto de vacas da raça Holandesa.

O tratamento com rbST no período seco das vacas aumentou a concentração de IGF-I no colostro, sem influência nas secreções lácteas subseqüentes.

A flutuação de IGF-I e IgG séricos é semelhante no período pré-parto de vacas da raça Holandesa. 


\section{Literatura Citada}

BAUMAN, D.E.; PEEL, C.J.; STEINHOUR, W.D. et al. Effect of bovine somatotropin on metabolism of lactating dairy cows: influence on rates of irreversible loss and oxidation of glucose and nonesterified fatty acids. Journal of Nutrition, v.118, n.8, p.1031-1040, 1988.

BAUMRUCKER, C.R.; BLUM, J.R. Secretion of insulin-like growth factors in milk and their effect on the neonate. Livestock Production Science, v.35, n.1/2, p.49-72, 1993.

BESSER, T.E.; GARMEDIA, A.E.; McGUIRE, T.C. Effects of colostral immunoglobulin $G_{1}$ and immunoglobulin $M$ concentrations on immunoglobulin absorption in calves. Journal of Dairy Science, v.68, n.8, p.2033-2037, 1985.

BLUM, J.W.; HAMMON, H. Colostrum effects on the gastrointestinal tract, and on nutritional, endocrine and metabolic parameters in neonatal calves. Livestock Production Science, v.66, n.2, p.151-159, 2000.

BRANDON, M.R.; WATSON, D.L.; LASCELLES, A.K. The mechanism of transfer of immunoglobulins into mammary secretions of cows. Australian Journal of Experimental Biology and Medical Science, v.49, p.613-623, 1971.

BREIER, B.H.; GLUCKMAN, P.D.; BASS, J.J. Plasma concentrations of insulin-like growth factor-I and insulin in the infant calf: ontogeny and influence of altered nutrition. Journal of Endocrinology, v.119, n.1, p.43-50, 1988.

BURTON, J.L.; KENNEDY, B.W.; BURNSIDE, B.N. et al. Variation in serum concentrations of immunoglobulins $G, A$ and $\mathrm{M}$ in Canadian Holstein-Friesian calves. Journal of Dairy Science, v.72, n.1, p.135-149, 1989.

BURTON, J.L.; McBRIDE, B.W.; BLOCK, E. et al. A review of bovine growth hormone. Canadian Journal of Animal Science, v.74, n.2, p.167-201, 1994.

BURTON, J.L.; McBRIDE, B.W.; KENNEDY, B.W. et al. Contact sensitivity and systemic antibody responses in dairy cows treated with recombinant bovine somatotropin. Journal of Dairy Science, v.75, n.3, p.747-755, 1992.

BURTON, J.L.; McBRIDE, B.W.; KENNEDY, B.W. et al. Influence of exogenous bovine somatotropin on the responsiveness of peripheral blood lymphocytes to mitogen. Journal of Dairy Science, v.74, n.3, p.916-928, $1991 \mathrm{~b}$.

BURTON, J.L.; McBRIDE, B.W.; KENNEDY, B.W. et al. Serum immunoglobulin profiles of dairy cows chronically treated with recombinant bovine somatotropin. Journal of Dairy Science, v.74, n.5, p.1589-1598, 1991a.

CAMPBELL, P.G.; SKAAR, T.C.; VEGA, J.R. et al. Secretion of insulin-like growth factor-I (IGF-I) and IGF-binding proteins from bovine mammary tissue in vitro. Journal of Endocrinology, v.128, n.2, p.219-228, 1991.

DIXON, F.J.; WEIGLE, W.O.; VAZQUEZ, J.J. Metabolism and mammary secretion of serum proteins in the cow. Laboratory Investigation, v.10, n.2, p.216-236, 1961.

DONOVAN, S.M.; McNEIL, L.K.; JIMÉNEZ-FLORES, R. et al. Insulin-like growth factors and insulin-like growth factor binding proteins in porcine serum and milk throughout lactation. Pediatric Research, v.36, n.2, p.159-168, 1994.

FLEENOR, W.A.; STOTT, G.H. Hydrometer test for estimation of immunoglobulin concentration in bovine colostrum. Journal of Dairy Science, v.63, n.6, p.973-977, 1980.

FOLEY, J.A.; OTTERBY, D.E. Availability, storage, treatment composition and feeding value of surplus colostrum: A Review. Journal of Dairy Science, v.61, n.8, p.1033-1060, 1978.
GALLO, G.F.; BLOCK, E. Effects of recombinant bovine somatotropin on nutritional status of dairy cows and of their calves. Journal of Dairy Science, v.73, n.11, p. 32663275, 1990.

GLIMM, D.R.; BARACOS, V.E.; KENNELLY, J.J. Effect of bovine somatrotopin on the distribution of immunoreactive insulin-like growth factor-I in lactating mammary tissue. Journal of Dairy Science, v.71, n.11, p.2923-2935, 1988.

GROSVENOR, C.E.; PICCIANO, M.F.; BAUMRUCKER, C.R. Hormones and growth factors in milk. Endocrine Reviews, v.14, n.6, p.710-728, 1993.

GULAY, M.S.; HAYEN, M.J.; BACHMAN, K.C. et al. Milk production and feed intake of Holstein cows given short (30d) or normal (60-d) dry periods. Journal of Dairy Science, v.86, n.6, p.2030-2038, 2003.

HADSELL, D.L.; BAUMRUCKER, C.R.; KENSINGER, R.S. Effects of elevated blood insulin-like growth factor-I (IGF-I) concentration upon IGF-I in bovine mammary secretions during the colostrum phase. Journal of Endocrinology, v.137, n.2, p.223-230, 1993.

HADSELL; D.L.; CAMPBELL, P.G.; BAUMRUCKER, C.R. Characterization of the change in type I and II insulin-like growth factor receptors of bovine mammary tissue during the pre and postpartum periods. Endocrinology, v.126, n.1, p.637-643, 1990.

HAMMON, H.M.; ZANKER, I.A.; BLUM, J.W. Delayed colostrum feeding affects IGF-I and insulin plasma concentrations in neonatal calves. Journal of Dairy Science, v.83, n.1, p.85-92, 2000.

HARDON, U.; HAMMON, H.; BRUCKMAIER, R.M. et al. Delaying colostrum intake by one day has important effects on metabolic traits and on gastrointestinal and metabolic hormones in neonatal calves. Journal of Nutrition, v.127, n.10, p.2011-2023, 1997.

HOSSNER, K.L.; McCUSKER, R.H.; DODSON, M.V. Insulinlike growth factors and their binding proteins in domestic animals. Animal Science, v.64, n.1, p.1-15, 1997.

HUSBAND, A.J.; BRANDON, M.R.; LASCELLES, A.K. Absorption and endogenous production of immunoglobulins in calves. Australian Journal of Experimental Biology and Medical Science, v.50, n.4, p.491-498, 1972.

JEFFCOTT, L.B. Passive immunity and its transfer with special reference to the horse. Biological Reviews, v.47, n.4, p.439-464, 1972.

KRUSE, P. E. Absorption of immunoglobulin from colostrum in newborn calves. Animal Production, v.12, n.4, p.627638, 1970

LANNA, D.P.D.; HOUSEKNECHT, K.L.; HARRIS, D.M. et al. Effects of somatotropin treatment on lipogenesis, lipolysis and related cellular mechanisms in adipose tissue of lactating cows. Journal of Dairy Science, v.78, n.8, p.1703-1712, 1995.

LARSON, B.L.; KENDALL, K.A. Changes in specific blood serum protein levels associated with parturition in the bovine. Journal of Dairy Science, v.40, n.6, p.659-666, 1957.

LeROITH, D.L. Insulin-like growth factor. Hormone and Metabolic Research, v.31, n.2/3, p.41-42, 1999.

MACEWKO, N.; ANGLISS, G.A.; JONES, E.F. et al. The influence of pre-calving somatotropin on the quantity and quality of colostrum in beef cattle. Journal of Dairy Science, v.85, n.1, p.353, 2002.

MACHADO NETO, R.; PACKER, I.U.; BONILHA, L.M. et al. Concentração de $\operatorname{IgG}$ sérica em bezerros das raças Nelore, 
Guzerá, Gir e Caracu. 2. Efeitos sobre crescimento e mortalidade até a desmama. Revista Brasileira de Zootecnia, v.26, n.5, p.920-923, 1997.

MALVEN, P.V.; HEAD, H.H.; COLliER, R.J. et al. Periparturient changes in secretion and mammary uptake of insulin and in concentrations of insulin and insulin-like growth factors in milk of dairy cows. Journal of Dairy Science, v.70, n.11, p.2254-2265, 1987.

MANCINI, G.; CARBONARA, A.O.; HERMANS, J.F. Immunochemical quantitation of antigens by single radial immunodiffusion. Immunochemistry, v.2, n.3, p.253254, 1965.

MORIN, D.E.; CONSTABLE, P.D.; MAUNSELL, F.P. et al. Factors associated with colostral specific gravity in dairy cows. Journal of Dairy Science, v.84, n.4, p-937-943, 2001.

NOCEK, J.E.; BRAUND, D.G.; WARNER, R.G. Influence of neonatal colostrum administration, immunoglobulin, and continued feeding colostrum on calf gain, health and serum protein. Journal of Dairy Science, v.67, n.2, p.319-333, 1984.

ODLE, J.; ZIJLSTRA, R.T.; DONOVAN, S.M. Intestinal effects of milk borne growth factors in neonates of agricultural importance. Journal of Animal Science, v.74, n.10, p.2509-2522, 1996.

PAULETTI, P.; MACHADO NETO, R.; PACKER, I.U. et al. Avaliação de níveis séricos de imunoglobulina, proteína e o desempenho de bezerras da raça Holandesa. Pesquisa Agropecuária Brasileira, v.37, n.1, p.89-94, 2002.

PROSSER, C.G.; FLEET, I.R.; CORPS, A.N. Increased secretion of insulin-like growth factor-I into milk of cows treated with recombinantly derived growth hormone. Journal of Dairy Research, v.56, n.1, p.17-26, 1989.

PUTNAM, D.E.; VARGA, G.A.; DANN, H.M. Metabolic and production responses to dietary protein and exogenous somatotropin in late gestation dairy cows. Journal of Dairy Science, v.82, n.5, p.982-995, 1999.

QUIGLEY, J.D.; DREWRY, J.J. Nutrient and immunity transfer from cow to calf pre- and postcalving. Journal of Dairy Sicence, v.81, n.10, p.2779-2790, 1998.

QUIGLEY, J.D.; KOST, C.J.; WOLFE, T.M. Absorption of protein and $\mathrm{IgG}$ in calves fed a colostrum supplement or replacer. Journal of Dairy Science, v.85, n.5, p.12431248, 2002.

REINHOLD, J.G. Total protein, albumin and globulin. In: REINER, M. (Ed.) Standard methods of clinical chemistry. New York: Academic Press, 1953. p.88.

RONGE, H.; BLUM, J.W. Somatomedin C and other hormones in dairy cows around parturition, in newborn calves and in milk. Journal of Animal Phisiology and Animal Nutrition, v.60, n.3, p.168-176, 1988.

ROSI, F.; PINOTTI, L. Slow-release somatotropin reduces plasma leptin in lactating dairy cows. Journal of Dairy Science, v.85, n.1, p.353, 2002.
STATISTICAL ANALYSES SYSTEM-SAS.SAS/STAT: user's guide. release 6.08 Cary: 1991. 1028p.

SASAKI, M.; DAVIS, C.L.; LARSON, B.L. Production and turnover of $\mathrm{IgG}_{1}$ and $\mathrm{IgG}_{2}$ immunoglobulins in the bovine around parturation. Journal of Dairy Science, v.59, n.12, p. 2046-2055, 1976.

SCHMIDT, G.H. Biology of lactation. San Francisco: W.H. Freeman, 1971. 317p.

SEJRSEN, K.; PEDERSEN, L.O.; VESTERGAARD, M. et al. Biological activity of bovine milk. Contribution of IGF-I and IGF binding proteins. Livestock Production Science, v.70, n. $1 / 2$, p.79-85, 2001.

SIMMEN, F.A.; SIMMEN, R.C.M.; REINHART, G. Maternal and neonatal somatomedin C/insulin-like growth factor-I (IGF-I) and IGF biding proteins during early lactation in the pig. Developmental Biology, v.130, n.1, p.16-27, 1988.

SMITH, R.D.; SNIFFEN, C.J.; PERKINS, B.L. Body condition scoring: a tool to use in herd analysis and management. Ithaca: Cornell University, Department of Animal Science, 1982. 8p.

TYLER, J.W.; STEEVENS, B.J.; HOSTELER, D.E. et al. Colostral immunoglobulin concentrations in Holstein and Guernsey cows. American Journal of Veterinary Research, v.60, n.9, p.1136-1139, 1999.

VACHER, P.Y.; BLUM, J.W. Age dependency of insulin-like growth factor-I, insulin, protein and immunoglobulin concentration and g-glutamyltransferase activity in first colostrum of dairy cows. Milk Science International, v.48, n.8, p.423-426, 1993.

VALLIMONT, J.E.; VARGA, G.A.; ARIELI, A. et al. Effects of prepartum somatotropin and monensin on metabolism and production of periparturient Holstein dairy cows. Journal of Dairy Science, v.84, n.12, p.2607-2621, 2001.

VEGA, J.R.; GIBSON, C.A.; SKAAR, T.C. et al. Insulin-like growth factor (IGF)-I and IGF binding proteins in serum and mammary secretions during the dry period and early lactation in dairy cows. Journal of Animal Science, v.69, n.6, p.2538-2547, 1991.

WEBER, M.S.; PURUP, S.; VESTERGAARD, M. et al. Regulation of local synthesis of insulin-like growth factor-I and binding proteins in mammary tissue. Journal of Dairy Science, v.83, n.1, p.30-37, 2000

ZHAO, X.; GROENWEGEN, P.P.; McBRIDE, B.W. et al. Radioimmunoassay for insuilin-like growth factor-I in bovine milk. Canadian Journal of Animal Science, v.71, n.3, p.669-674, 1991.

Recebido em: 17/04/04 Aceito em: 10/03/05 